This is a self-archived - parallel published version of this article in the publication archive of the University of Vaasa. It might differ from the original.

\title{
Islanding detection during intended island operation of nested microgrid
}

Author(s): Laaksonen, Hannu; Hovila, Petri

Title: Islanding detection during intended island operation of nested microgrid

Year: $\quad 2018$

Version: Accepted manuscript

Copyright (C)2018 IEEE. Personal use of this material is permitted. Permission from IEEE must be obtained for all other uses, in any current or future media, including reprinting/republishing this material for advertising or promotional purposes, creating new collective works, for resale or redistribution to servers or lists, or reuse of any copyrighted component of this work in other works.

Please cite the original version:

Laaksonen, H., \& Hovila, P., (2018). Islanding detection during intended island operation of nested microgrid. In: 2018 IEEE PES Innovative Smart Grid Technologies Conference Europe (ISGT-Europe), Sarajevo (pp. https://doi.org/10.1109/ISGTEurope.2018.8571571 


\section{Islanding Detection During Intended Island Operation of Nested Microgrid}

\author{
Hannu Laaksonen \\ University of Vaasa \\ Vaasa, Finland \\ hannu.laaksonen@uva.fi
}

\author{
Petri Hovila \\ Medium Voltage Products, ABB Oy \\ Vaasa, Finland \\ petri.hovila@fi.abb.com
}

\begin{abstract}
In the future, functionalities like islanding detection must also operate during intended island operation of (MV+MV or $M V+L V$ ) nested microgrids. In this paper, healthy and faulty islanding detection of $L V$ network connected generation unit during nested $(M V+L V)$ microgrid islanded operation were studied by simulations with PSCAD model from real-life smart grid pilot. Main focus in the simulations was on the study and comparison of usage possibilities of combined (high-speed communication based transfer trip \& fault detection/direction + voltage vector shift) and multi-criteria (voltage total harmonic distortion \& voltage unbalance) based islanding detection schemes also during intended island operation of nested microgrid consisting only from inverter based generation units.
\end{abstract}

Index Terms-- Microgrids, Power system protection, Distributed power generation, Islanding

\section{INTRODUCTION}

\section{A. Islanding Detection During Island Operation}

Intelligent utilization of controllable, flexible, distributed energy resources (DER) will be in main role to enable more resilient power system. Key components in future power systems will be different electricity network subsystems with flexible resources like, for example, nested microgrids (e.g. MV microgrid including multiple MV and/or LV microgrids). Coordinated use of flexible resources in nested microgrids for different technical services during grid-connected and islanded operation enables improvement of local and system-wide grid resiliency [1]. During transmission or distribution network downtimes due to storms, natural disasters or external attacks (physical or cyber) microgrid with flexible resources can still continue electricity supply to customers in islanded operation mode. However, this also creates needs for network management and protection methods and solutions which have to be adapted and developed in order to enable utilization of intended island operation as well as active control and utilization flexibilities during grid-connected and islanded operation modes [2]-[8]. One functionality which will be still needed also during intended island operation of nested microgrids is the islanding detection [9]. In general, during islanded operation only circuit-breaker (CB) status change and high-speed transfer trip based islanding detection could be enough if only $\mathrm{CB}$ status position based detection is allowed. However, if it is not allowed then one possibility could be to utilize combined islanding detection scheme (Fig. 1) also during islanded microgrid operation as proposed in [9]. However, there can be differences in the dynamic behavior of the islanded microgrid when compared to grid-connected operation. Therefore, it is not obvious that the same combined islanding detection scheme [9] is also valid during islanded microgrid operation. For example, if traditional synchronous generator (SG) based generating units, are be connected in microgrid, then it could be expected that islanding can be detected even more rapidly with same e.g. voltage vector shift (VVS) settings as in grid-connected mode due to more sensitive dynamics during islanded operation. But if island operated network is formed only by inverter connected DER units which are controlled very rapidly in a "grid-forming" way (in terms of frequency and voltage) to ensure stability in every situation during islanded operation, then islanding detection with VVS based method may become challenging.

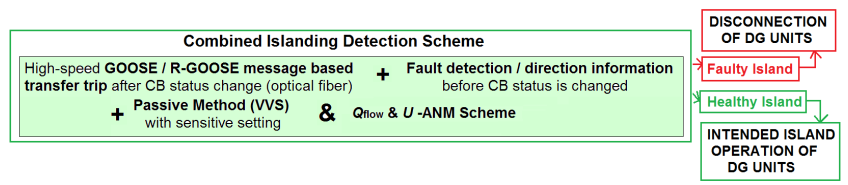

Figure 1. Studied combined islanding detection scheme.

Islanding detection can require very sensitive settings and rapid operation because VVS detection is based on the changing voltage angle / frequency. Therefore, possibilities to utilize multi-criteria (voltage total harmonic distortion $U_{\text {THD }} \&$ voltage unbalance VU) based islanding detection scheme [10] could be also further examined if DER units in the islanded $(\mathrm{MV}+\mathrm{MV}$ or $\mathrm{MV}+\mathrm{LV})$ nested microgrid are not controlled to compensate voltage unbalance.

\section{B. Sundom Smart Grid and Future Protection and Control Functionalities}

In this paper, islanding detection of LV network connected DG unit during nested $(\mathrm{MV}+\mathrm{LV})$ microgrid islanded operation is studied by PSCAD simulations with model from Sundom Smart Grid (SSG) (Fig. 2). SSG is a smart grid pilot of ABB Oy, Vaasan Sähkö (local DSO), Elisa (telecommunication 
company, previously Anvia) and University of Vaasa. SSG acts as Finnish Innovation Cell (IC) in DeCAS project. In SSG IEEE 1588 time-synchronized, more accurate IEC 61850-9-2 sampled values (SVs) and less accurate GOOSE values based, measurement data from multiple points is collected and stored in servers to enable research and development of active network management (ANM), protection and islanding detection functionalities. Nowadays there are two distributed generation (DG) units connected in SSG (Fig. 2). Full-powerconverter connected wind turbine (3.6 MW) in MV network with own MV feeder J08 (Fig. 2) and inverter based PV unit $(33 \mathrm{~kW})$ in $\mathrm{LV}$ network connected at $\mathrm{MV} / \mathrm{LV}$ substation TR4318 (Fig. 2).

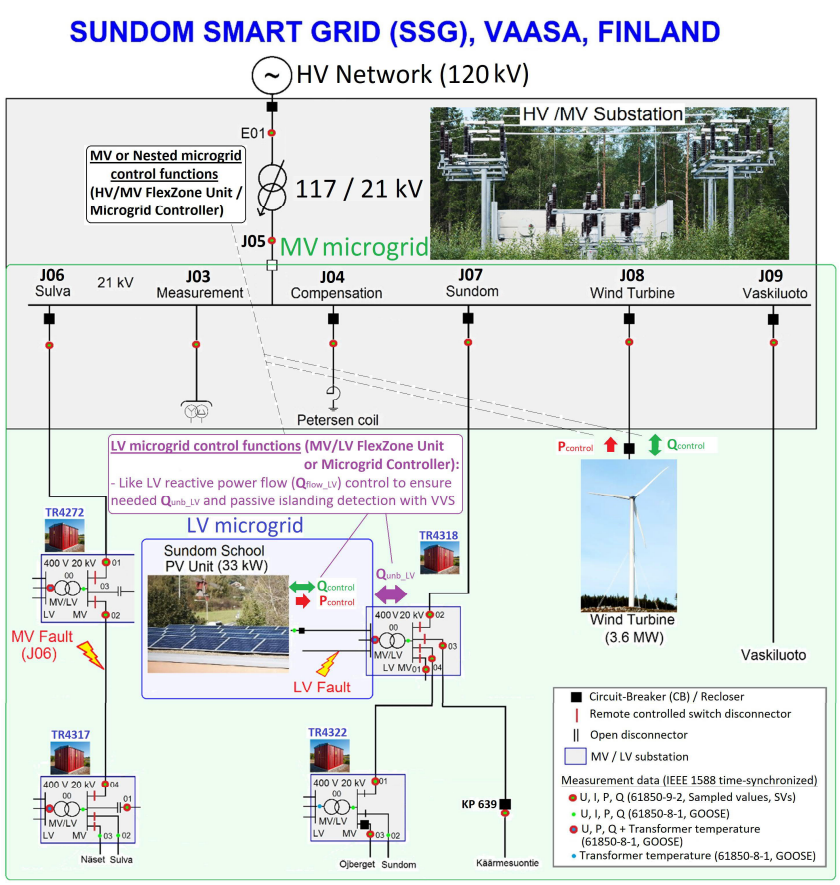

Figure 2. Sundom Smart Grid (SSG) in which islanding detection of LV network connected DG unit during nested $(\mathrm{MV}+\mathrm{LV})$ microgrid islanded operation is studied.

Fig. 3 shows that based on real-life GOOSE measurements (Fig. 2), operation in active $(P)$ and reactive $(Q)$ power balance as well as in intended MV network island operation is possible in SSG if DER units and other flexible resources are properly controlled.

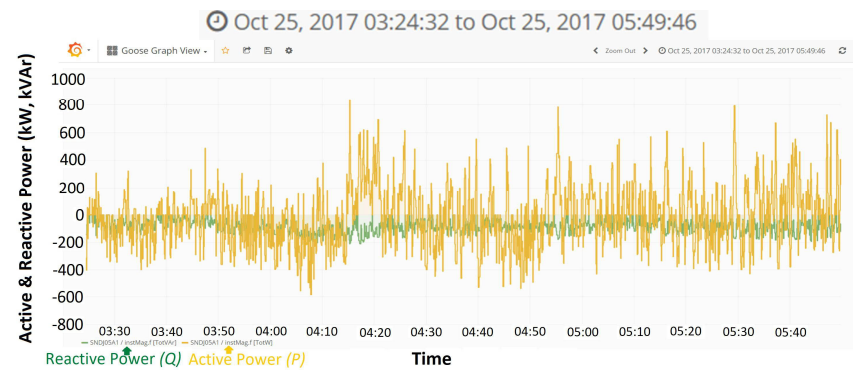

Figure 3. Measured active and reactive power flows through circuit-breaker (CB) J05 at Sundom HV/MV substation (Fig. 2).

As presented in [9], [11] and [12] active management of reactive power unbalance $Q_{\text {unb_LV }}$ (Fig. 2) can be used to enable reliable islanding detection e.g. based on VVS alone or as part of combined scheme [9]. Needed reactive power unbalance $Q_{\text {unb_Lv }}$ (Fig. 2) can be, for example, +/- 30-50 $\mathrm{kVAr}$ through the circuit-breaker $(\mathrm{CB}) /$ protective device (PD) at the LV side of MV/LV transformer to always ensure islanding detection. In SSG (Fig. 2) during intended MV microgrid island operation reactive power control of LV network connected PV unit could be used to maintain $Q_{\text {unb_LV }}$ outside non-detection zone (NDZ) of VVS (if it is used for islanding detection). However, potentially also reactive power control of converter/inverter interfaced loads, energy storages etc. inside LV microgrid (Fig. 2) could be used for

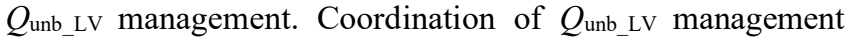
and other LV and MV microgrid control functionalities (Fig. 2 ) in nested microgrids could be performed with MV/LV and HV/MV FlexZone Units (FZUs) as proposed in [1]. These $\mathrm{HV} / \mathrm{MV}$ and MV/LV FZUs could include, in addition to different ANM functionalities, also other 'centralized' functionalities like protection/fault indication \& fault location, islanding detection \& logic, status monitoring, predictive protection, available flexibilities, flexibility forecasts and historian from flexibilities control/use. However, coordinated operation and interoperability of FZUs in different levels needs to be ensured in all situations. [1]

Fig. 4 presents future target schematics of these HV/MV and MV/LV FZU [1] functionalities mapped to SGAM (i.e. Smart Grid Architecture Model that shows the different layers of interoperability.). In the future, one alternative could be that some of the less critical / high-speed communication dependent DSO FZU functionalities (Fig. 4) like, for example, monitoring or predictive protection related big data solutions, flexibility forecasts, some ANM schemes etc. would be alternatively located in cloud servers. This approach could enable more flexible and scalable solutions when only most communication and time-critical protection and islanding detection applications would remain at actual HV/MV or MV/LV FZUs. [1]

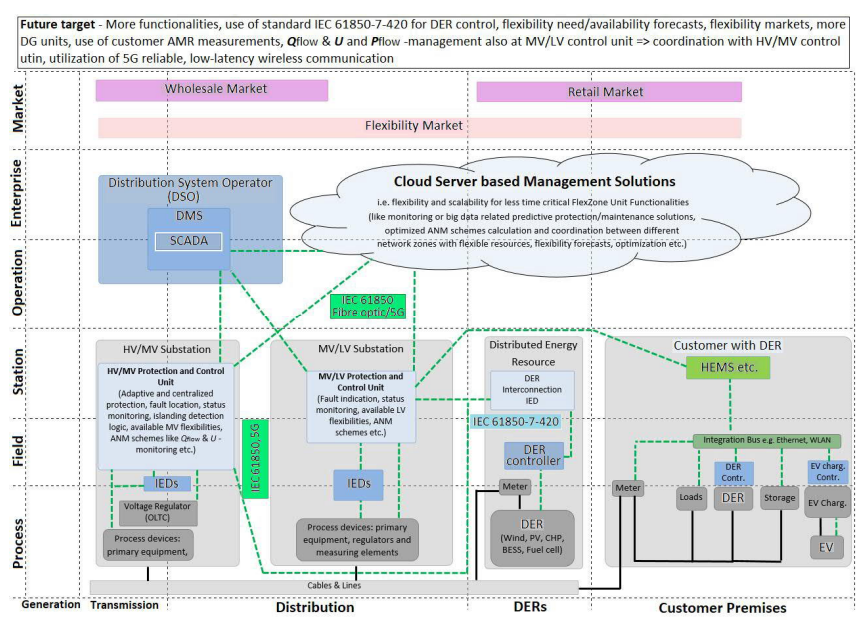

Figure 4. Future target of HV/MV and MV/LV FlexZone Unit [1] functionalities mapped to SGAM. [13] 


\section{Simulation CASES AND Results}

In following some chosen PSCAD simulation study cases and results regarding healthy or faulty islanding detection of LV network connected DG unit during nested $(\mathrm{MV}+\mathrm{LV})$ microgrid islanded operation in SSG (Fig. 2) are presented. Primarily the possibility to utilize combined islanding detection scheme [9] (high-speed communication based transfer trip \& fault detection/direction + VVS) also during intended island operation of nested microgrid with normal prioritization [9] will be studied in the simulations. As part of the combined islanding detection scheme, the possibility to take the fault location and direction into account also during islanded operation will be considered in order to rapidly disconnect only faulted microgrid zone/section and to prevent false disconnection of DG units in the healthy microgrid zones. However, also the potential of multi-criteria (voltage total harmonic distortion $U_{\mathrm{THD}} \&$ voltage unbalance $\mathrm{VU}$ ) based islanding detection scheme [10], [14], [15] will be studied for comparison purposes.

In the previous papers [6] and [16] protection scheme for neutral isolated, MV microgrid with mainly overhead $(\mathrm{OH})$ lines and converter-based DG units having multiple protection zones was presented. However, in this paper the SSG MV microgrid earthing method is compensated (resonant grounding) and MV network consists from both $\mathrm{OH}$ lines and cables. Therefore, the earth-fault location and direction determination as part of the islanding detection logic during intended MV microgrid island operation may need some changes when compared to [6] and [16].

\section{A. Healthy LV Islanding Without Fault During Islanded Operation of SSG}

In Fig. 5 frequency, positive sequence voltage $\left(U_{1}\right)$ and VVS at the connection point of LV network DG unit (PV) during islanded operation of SSG (Fig. 2) in five different healthy LV islanding detection cases without fault (islanding at $t=5.0 \mathrm{~s}$ ) are presented.

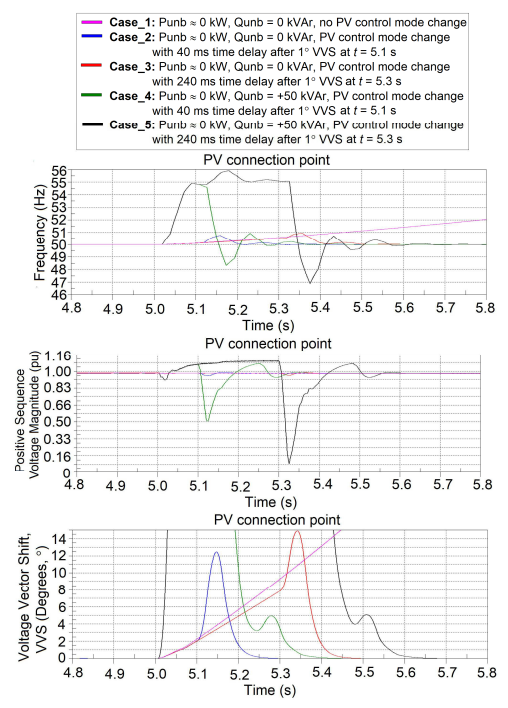

Figure 5. Frequency, positive sequence voltage $U_{1}$ and VVS at the connection point of LV network DG unit (PV) during islanded operation of SSG (Fig. 2) in five different healthy LV islanding detection cases without fault, islanding at $\mathrm{t}=5.0 \mathrm{~s}$.
Respectively, Fig. 6 shows voltage total harmonic distortion $U_{\text {THD }}$ of phase A and voltage unbalance $\mathrm{VU}$ from these five cases.

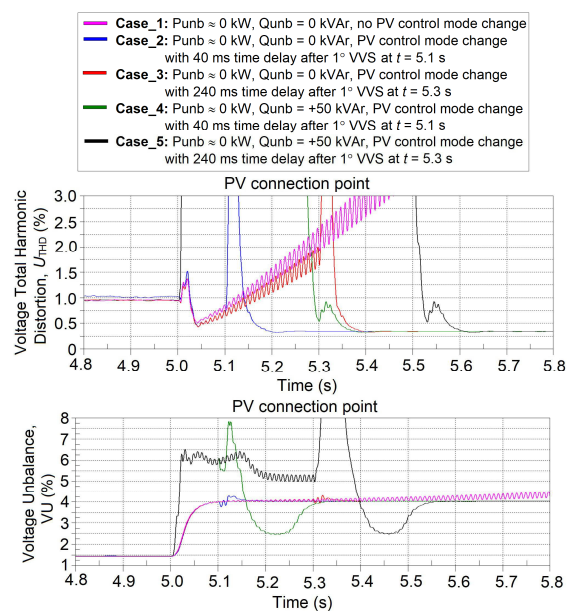

Figure 6. Voltage total harmonic distortion $U_{\text {THD }}$ of phase A and voltage unbalance VU at the connection point of LV network DG unit (PV) during islanded operation of SSG (Fig. 2) in five different healthy LV islanding detection cases without fault, islanding at $\mathrm{t}=5.0 \mathrm{~s}$.

From simulation results (Fig. 5) it can be seen that rapid enough $(<100 \mathrm{~ms})$ islanding detection can be achieved with combined scheme [9] with VVS setting $1^{\circ}$ in all cases even near total active and reactive power balance. On the other hand, from Fig. 6 it can be seen that based on these simulations, the use of voltage total harmonic distortion $U_{\mathrm{THD}}$ for rapid multi-criteria based islanding detection [10], [14], [15] can be challenging. Fig. 5 also shows how $U_{1}$ momentarily drops in Case 4 and 5 when compared to Case 2 due to $+50 \mathrm{kVAr}$ reactive power unbalance before islanding and $200 \mathrm{~ms}$ longer time delay in control mode change of PV unit. Therefore, PV control mode change from grid-following / slave to grid-forming / master should be performed as rapidly as possible.

\section{B. No LV Islanding After MV Fault During Islanded Operation of SSG}

In Fig. 7 frequency, VVS, $U_{\text {THD }}$ and VU in three different cases without LV islanding after MV fault during islanded operation of SSG (Fig. 2) are shown.

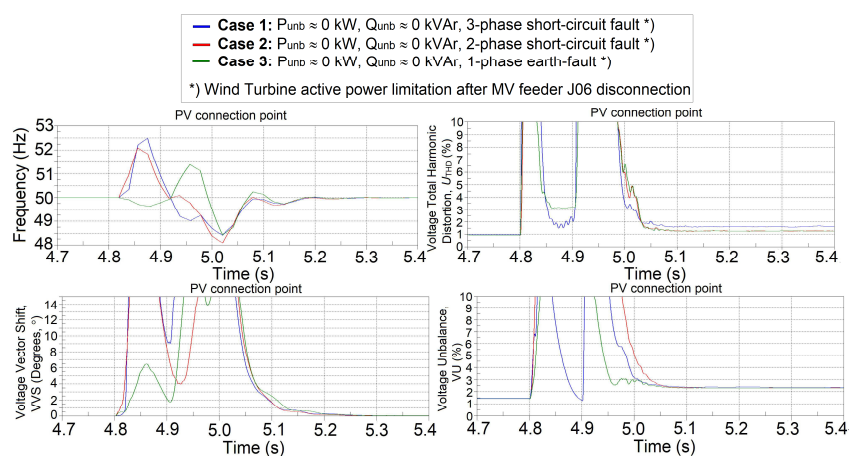

Figure 7. Frequency, VVS, voltage total harmonic distortion $U_{\text {THD }}$ of phase A and voltage unbalance VU at the connection point of LV network DG unit (PV) during islanded operation of SSG (Fig. 2) in three different MV fault cases without LV islanding (100 ms MV feeder J06 fault at $t=4.8 \mathrm{~s}$ before CB J06 opens at $t=4.9 \mathrm{~s})$. 
Fig. 8 presents positive, negative and zero sequence voltages at the connection point of LV network DG unit (PV) during islanded operation of SSG (Fig. 2) in these three different MV fault cases without LV islanding (100 ms MV feeder J06 fault at $t=4.8 \mathrm{~s}$ before CB J06 opens at $t=4.9 \mathrm{~s}$ ).
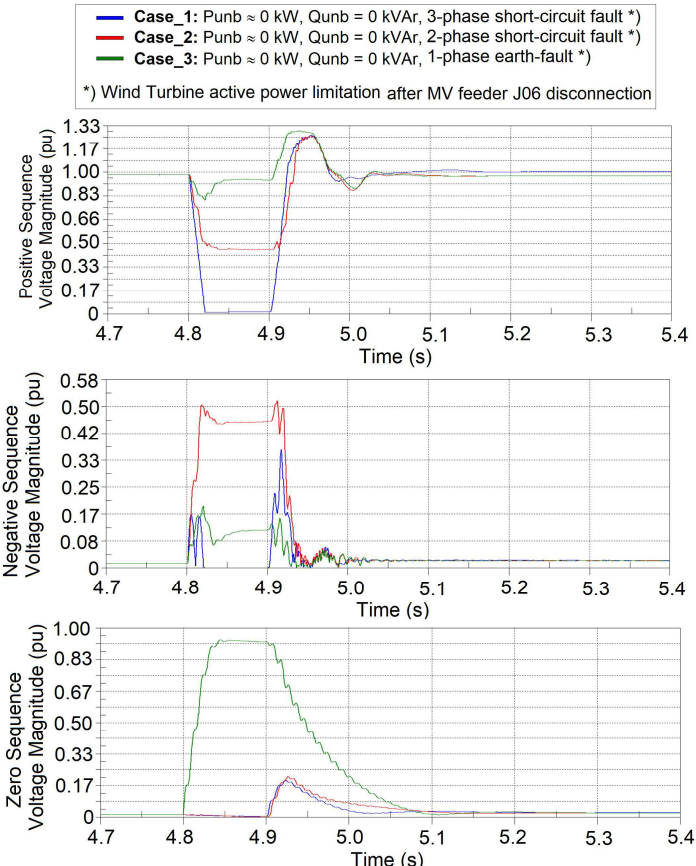

Figure 8. Positive, negative and zero sequence voltages at the connection point of LV network DG unit (PV) during islanded operation of SSG (Fig. 2) in three different MV fault cases without LV islanding (100 ms MV feeder J06 fault at $t=4.8 \mathrm{~s}$ before CB J06 opens at $t=4.9 \mathrm{~s}$ ).

Respectively, Fig. 9 shows positive, negative and zero sequence current magnitudes $\left(I_{1}\right.$ mag, $I_{2}$ mag and $\left.I_{0_{-} \text {mag }}\right)$ as well as $U_{1}$ angle $-I_{1}$ angle, $U_{2}$ angle- $I_{2}$ angle and $U_{\text {o_angle }} I_{\text {o_angle }}$ during islanded operation of SSG (Fig. 2) in these three cases.

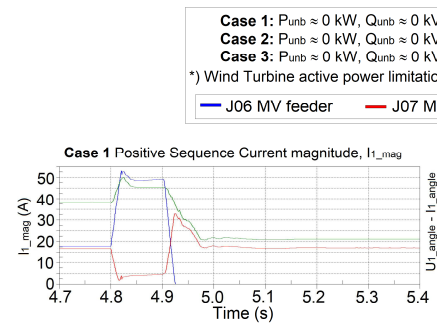

$$
\begin{aligned}
& 0 \mathrm{kVAr} \text {, 3-phase short-circuit fault * } \\
& 0 \mathrm{kVAr} \text {, } \\
& 0 \text {-phase short-circuit fault * } \\
& 0 \mathrm{kVAr}, \text {-phase earth-fault } \\
& \text { *) }
\end{aligned}
$$$$
\text { Case 2: }
$$

(a)
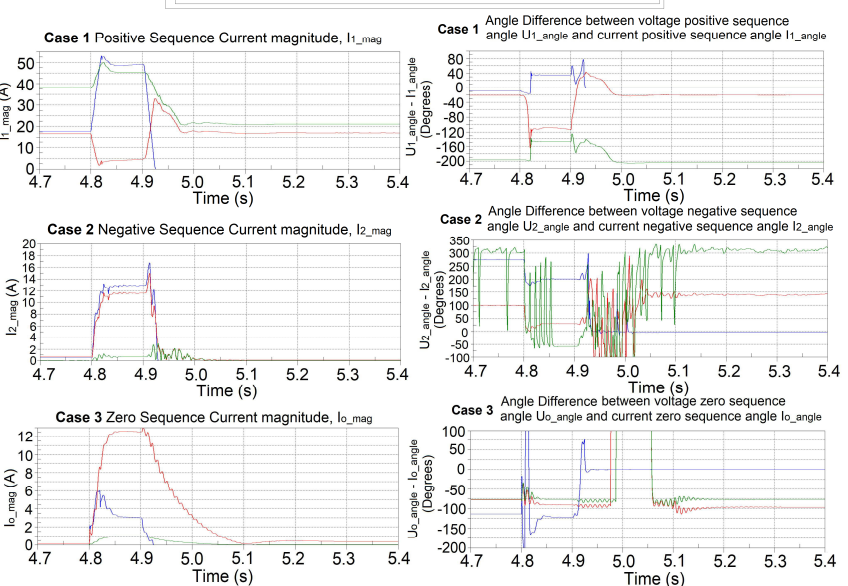

Figure 9. Positive, negative and zero sequence current magnitudes $\left(I_{1}{ }_{\mathrm{mag}}\right.$ $I_{2 \_ \text {mag }}$ and $I_{\mathrm{o}_{-} \text {mag }}$ ) as well as $U_{1 \_ \text {angle }}-I_{1_{\_} \text {angle }}, U_{2 \_ \text {angle }}-I_{2}$ angle and $U_{\mathrm{o}_{-} \text {angle }}-I_{\mathrm{o}_{-}}$angle during islanded operation of SSG (Fig. 2) in three different MV fault cases without LV islanding (100 ms MV feeder J06 fault at $t=4.8 \mathrm{~s}$ before CB J06 opens at $t=4.9 \mathrm{~s}$ ).
From simulation results in Fig. 7 it can be seen that the combined scheme with transfer trip as well as fault detection information (Fig. 8 and 9) is needed in order to prevent PV unit islanding detection maloperation.

\section{Healthy LV Islanding After MV Fault During Islanded Operation of SSG}

In Fig. 10 LV network primary islanding detection scheme for PV unit during islanded operation of SSG in one example case [9] (healthy LV islanding after MV fault) is presented.

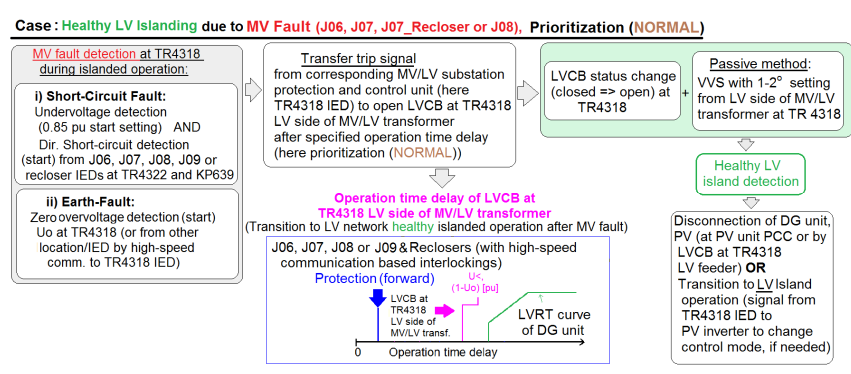

Figure 10. LV network DG unit (PV) primary islanding detection scheme example case (healthy LV islanding after MV fault) during islanded operation of SSG (Fig. 2). [9]

Fig. 11 shows frequency, positive sequence voltage $\left(U_{1}\right)$ and VVS at the connection point of LV network DG unit (PV) during islanded operation of SSG (Fig. 2) in two different healthy LV islanding detection cases with 3-phase shortcircuit MV fault at $\mathrm{J} 06$ at $t=4.8 \mathrm{~s}$ before islanding at $t=5.0 \mathrm{~s}$.
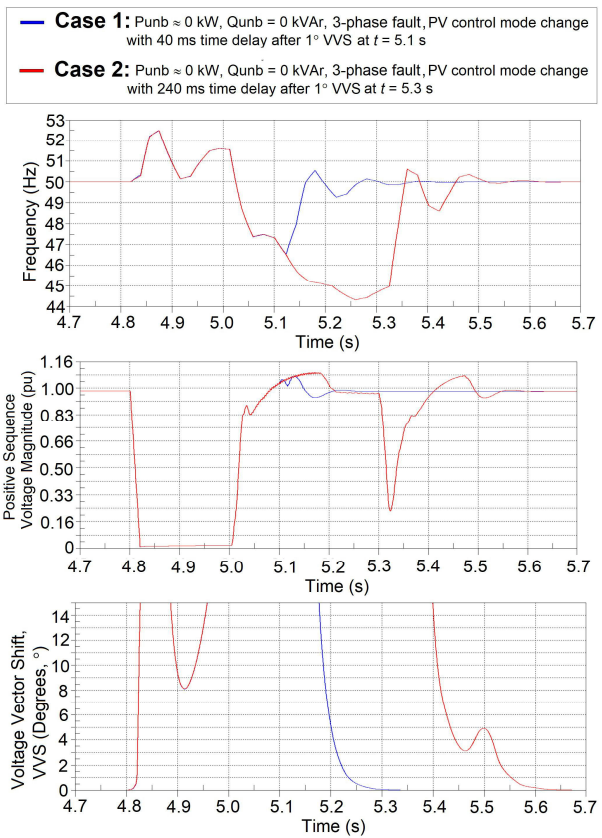

Figure 11. Frequency, positive sequence voltage $U_{1}$ and VVS at the connection point of LV network DG unit (PV) during islanded operation of SSG (Fig. 2) in two different healthy LV islanding after MV fault cases (3phase short-circuit MV fault at J06 at $t=4.8 \mathrm{~s}$ ), islanding at $\mathrm{t}=5.0 \mathrm{~s}$.

In Fig. $12 U_{\text {THD }}$ of phase A, VU and active and reactive power unbalance $P_{\text {unb_LV }}$ and $Q_{\text {unb_LV }}$ at the connection point of LV network DG unit (PV) during islanded operation of SSG 
(Fig. 2) in these two healthy LV islanding detection cases with 3-phase short-circuit MV fault are presented.
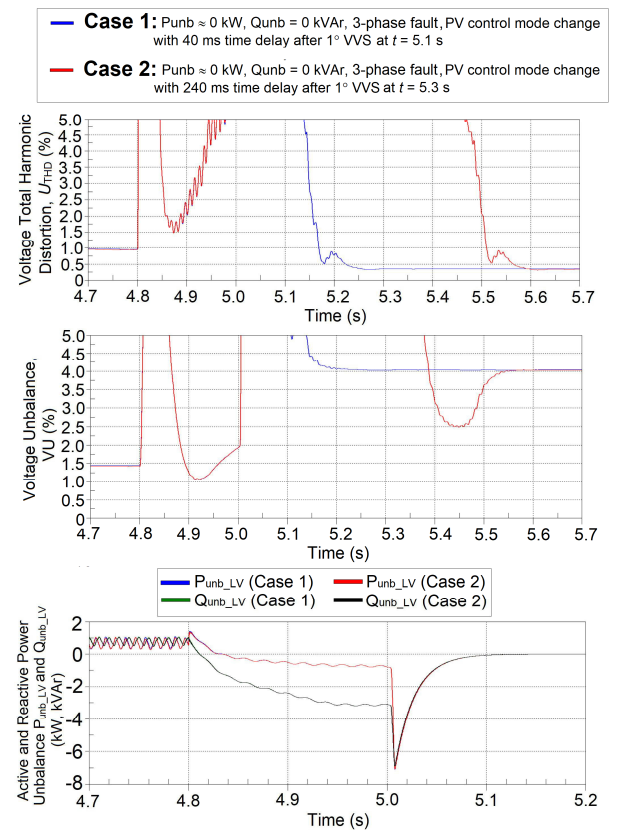

Figure 12. Voltage total harmonic distortion $U_{\mathrm{THD}}$ of phase A, voltage unbalance VU and active and reactive power unbalance $P_{\text {unb LV }}$ and $Q_{\text {unb LV }}$ at the connection point of LV network microgrid during islanded operation of SSG (Fig. 2) in two different healthy LV islanding after MV fault cases (3-

phase short-circuit MV fault at J06 at $t=4.8 \mathrm{~s}$ ), islanding at $\mathrm{t}=5.0 \mathrm{~s}$.

From simulation results (Fig. 11 and 12) it can be seen that healthy LV islanding detection after MV fault requires simultaneous fault detection and direction/location consideration also with combined scheme to ensure PV unit selective islanding detection. Fig. 5 also presents how $U_{1}$ decreases in Case 2 when compared to Case 1 due to $200 \mathrm{~ms}$ longer time delay in control mode change of PV unit. Time delay in control mode change from grid-following to gridforming leads in this case to increased angle difference and may prevent stable transition to LV microgrid (Fig. 2) islanded operation [17].

\section{Faulty LV Islanding After LV Fault During Islanded Operation of SSG}

Fig. 13 shows frequency, positive, negative and zero sequence voltages and VVS at the connection point of LV network DG unit (PV) during islanded operation of SSG (Fig. 2) in three different faulty LV islanding after LV fault cases (LV fault at $t=4.9 \mathrm{~s}$ and islanding at $t=5.0 \mathrm{~s}$ ). Respectively in Fig. 14 and $15 U_{\text {THD }}$ of phase A, voltage unbalance VU, active and reactive power unbalance $P_{\text {unb_LV }}$ and $Q_{\text {unb_LV }}$ and positive and negative sequence current magnitudes $\left(I_{1}\right.$ mag and $I_{2}$ mag $)$ as well as angle differences $U_{1 \_ \text {angle }} I_{1}$ angle and $U_{2}$ angle$I_{2}$ angle in these three different different faulty LV islanding after LV fault cases are presented. In these three different faulty LV islanding cases (Fig. 13-15) after LV fault (3-, 2- or 1-phase LV fault) LV network connected DG unit (PV) control mode is not changed after $1^{\circ}$ VVS detection, because control mode change is only activated after healthy (i.e. not after faulty) islanding and $1^{\circ} \mathrm{VVS}$ detection.

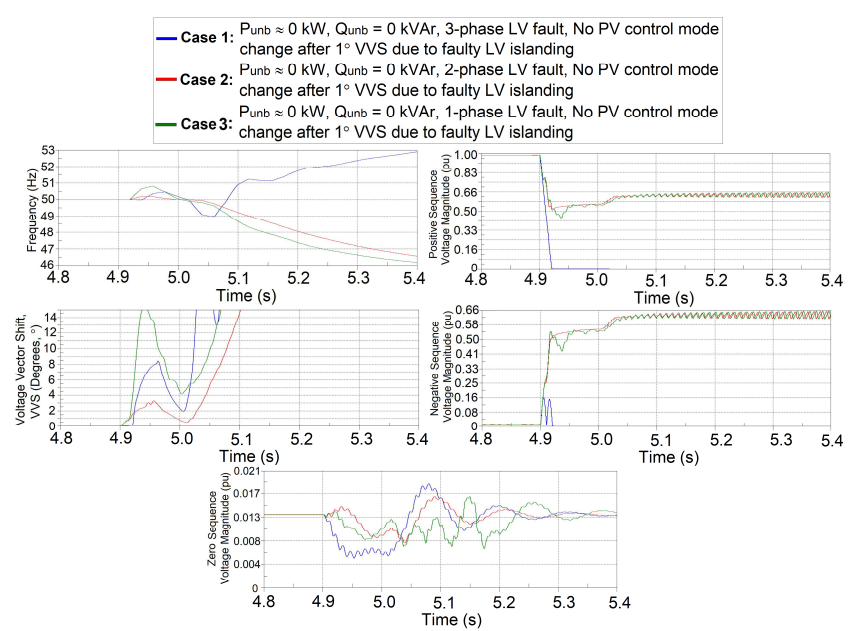

Figure 13. Frequency, positive, negative and zero sequence voltages and VVS at the connection point of LV network DG unit (PV) during islanded operation of SSG (Fig. 2) in three different faulty LV islanding after LV fault cases (LV fault at $t=4.9 \mathrm{~s}$ ), islanding at $\mathrm{t}=5.0 \mathrm{~s}$.

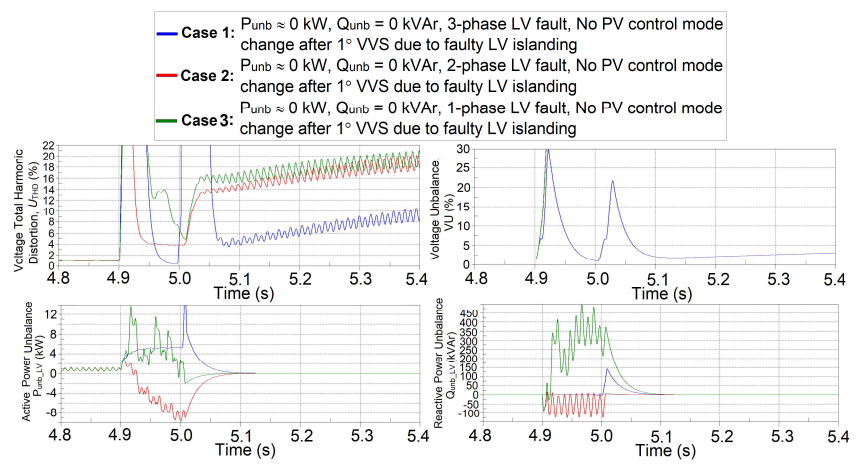

Figure 14. Voltage total harmonic distortion $U_{\text {THD }}$ of phase A, voltage unbalance VU and active and reactive power unbalance $P_{\text {unb LV }}$ and $Q_{\text {unb LV }}$ at the connection point of LV network DG unit (PV) during islanded operation of SSG (Fig. 2) in three different faulty LV islanding after LV fault cases (LV fault at $t=4.9 \mathrm{~s}$ ), islanding at $\mathrm{t}=5.0 \mathrm{~s}$.
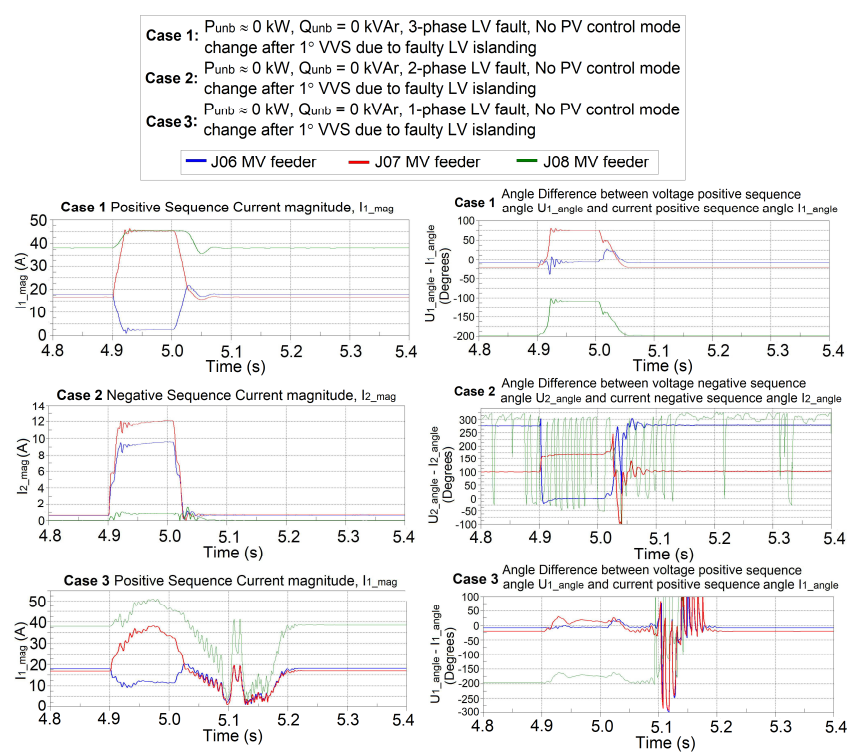

Figure 15. Positive and negative sequence current magnitudes $\left(I_{1 \mathrm{mag}}\right.$ and $I_{2} \mathrm{mag}$ ) as well as $U_{1}$ angle- $I_{1}$ angle and $U_{2}$ angle- $I_{2}$ angle during islanded operation of SSG (Fig. 2) in three different faulty LV islanding after LV fault cases (LV fault at $t=4.9 \mathrm{~s}$ ), islanding at $\mathrm{t}=5.0 \mathrm{~s}$. 
By comparing Fig. 9 and 15 one can see that it would be challenging to ensure selectivity during $\mathrm{MV}$ islanded operation between MV and LV faults based on purely current magnitudes. Therefore, in [6] and [16] it has been stated that admittance based adaptive (voltage dependent) start value of MV microgrid short-circuit protection scheme could be in order to ensure this selectivity. One alternative possibility to separate MV and LV faults selectively could be usage of powerflow $P_{\text {unb LV }}$ and/or $Q_{\text {unb LV }}$ behavior at the connection point of LV microgrid (see Fig. 12 and 14).

\section{DISCUSSION AND CONCLUSIONS}

Coordinated use of flexible resources in $(\mathrm{MV}+\mathrm{MV}$ or $\mathrm{MV}+\mathrm{LV}$ ) nested microgrids during islanded operation enables improved electricity supply to customers. This also requires that functionalities like islanding detection is also adapted to operate during intended island operation of nested microgrid. In this paper, healthy and faulty islanding detection of LV network connected DG unit during nested (MV+LV) microgrid islanded operation has been studied by simulations with PSCAD model from Sundom Smart Grid having only inverter based generation units. Main focus in the simulation was on the combined islanding detection scheme, but also the potential of multi-criteria based islanding detection scheme was studied.

Based on the simulations it can be concluded that combined islanding detection scheme seems to be very feasible for the islanding detection with LV network connected inverter based DG units in nested $(\mathrm{MV}+\mathrm{LV})$ microgrids. However, the fault detection logic should be adapted from grid-connected to islanded operation mode. On the other hand, in the simulations the steady-state value of $U_{\text {THD }}$ (multi-criteria algorithm parameter) decreased after healthy islanding. Therefore, as also stated in [14] with different type of MV and LV network, the use of VU alone could be more potential for islanding detection if DER units in the islanded microgrid are not controlled to compensate voltage unbalance. In addition, regardless of DER unit control method, selectivity of the VU only based method with connection of large single-phase loads could also be challenging during LV microgrid islanded operation. From the simulation results in Section II it was seen that $U_{\mathrm{THD}}$ before islanding (grid connected mode) was $0.5 \%$ and during intended MV microgrid island operation $1.0 \%$ and during LV microgrid island operation $0.35 \%$. This means that $U_{\text {THD }}$ was lowest during LV microgrid island operation and the main reason for this is that the loads in simple $\mathrm{LV}$ microgrid were quite simple (PV inverter with LCL-filter, one $400 \mathrm{~m}$ LV line and only passive loads (no thyristor, diode or frequency converter based loads). This means that existence of nonlinear loads in LV network would have improved the operation of multi-criteria based method. In addition, one notable difference, when compared to previous LV microgrid voltage and current THD studies with different DG unit and load configurations in [18], is that in this paper MV network is modelled with much more details and LV network with less details.

In the future, nested microgrid control and protection functionality could be centralized/de-centralized in control and protection units at $\mathrm{HV} / \mathrm{MV}$ and $\mathrm{MV} / \mathrm{LV}$ substations. For example, the fault detection and location determination could be coordinated between these units by using high-speed communication, real-time synchronized measurements from multiple locations simultaneously as well as knowledge about type, status and location of different DER units in order to ensure always selective islanding detection.

\section{ACKNOWLEDGMENTS}

This work was supported by DeCAS project (http://www.decas-project.eu/), which has received funding from the joint EU program ERA-Net Smart Grids Plus.

\section{REFERENCES}

[1] H. Laaksonen and P. Hovila, "FlexZone Concept to Enable Resilient Distribution Grids - Possibilities in Sundom Smart Grid," in Proc. CIRED 2016 Workshop, 2016.

[2] H. Laaksonen and K. Kauhaniemi, "Synchronized Re-Connection of Island Operated LV Microgrid Back to Utility Grid," in Proc. IEEE PES ISGT Europe 2010, 2010.

[3] H. Laaksonen, "Grid Code Compatible Protection Scheme for Smart Grids," in Proc. 23 $3^{\text {rd }}$ International Conference on Electricity Distribution (CIRED 2015), 2015.

[4] H. Laaksonen, K. Kauhaniemi and S. Voima, "Microgrid Voltage Level Management and Role as Part of Smart Grid Voltage Control," in Proc. IEEE PES PowerTech 2011 Conference, 2011.

[5] H. Laaksonen, "Protection Principles for Future Microgrids," IEEE Trans. Power Electronics, vol. 25, pp. 2910-2918, Dec. 2010.

[6] H. Laaksonen and P. Hovila, "Enhanced MV Microgrid Protection Scheme for Detecting High-Impedance Faults," in Proc. $12^{\text {th }}$ IEEE PES PowerTech 2017 Conference, 2017.

[7] H. Laaksonen, D. Ishchenko, and A. Oudalov, "Adaptive Protection and Microgrid Control Design for Hailuoto Island," IEEE Trans. Smart Grid, vol. 5, pp. 1486-1493, May 2014.

[8] CIGRE (Joint Working Group B5/C6.26/CIRED), "Protection of Distribution Systems with Distributed Energy Resources," 2015.

[9] H. Laaksonen and P. Hovila, "Future-proof Islanding Detection Schemes in Sundom Smart Grid," in Proc. 24 $4^{\text {th }}$ International Conference on Electricity Distribution (CIRED 2017), 2017.

[10] H. Laaksonen, "Advanced Islanding Detection Functionality for Future Electricity Distribution Networks," IEEE Trans. Power Delivery, vol. 28, pp. 2056-2064, 2013.

[11] H. Laaksonen, "Reliable Islanding Detection with Active MV Network Management," in Proc. CIRED Workshop 2014, 2014.

[12] H. Laaksonen, "Securing Passive Islanding Detection and Enabling Stable Islanding with $\mathrm{Q} / \mathrm{f}$-droop Control of DG Unit," International Review of Electrical Engineering (IREE), vol. 9, pp. 592-602, June 2014.

[13] A. Einfalt, C. Groiß, N. Thie, M. Vasconcelos, J. Helguero, H. Laaksonen, P. Hovila, and S. Übermasser, "Report on technical, market and stakeholder requirements," DeCAS -project Deliverable $1.1,2017$.

[14] H. Laaksonen, "New Multi-criteria-based Algorithm for Islanding Detection in Smart Grids," in Proc. IEEE PES ISGT Europe 2012, 2012.

[15] H. Laaksonen, "Enhanced Multi-Criteria-Based Passive Islanding Detection Scheme," International Review of Electrical Engineering (IREE), vol. 9, pp. 1162-1170, Dec. 2014.

[16] H. Laaksonen, "Protection Scheme for Island Operated MediumVoltage Microgrid," International Review of Electrical Engineering (IREE), vol. 10, pp. 510-519, Aug. 2015.

[17] H. Laaksonen, and K. Kauhaniemi, "Stability of Microgrid with Different Configurations after Islanding Due to Fault in the Utility Grid," International Review of Electrical Engineering (IREE), vol. 3, pp. 498-512, June 2008.

[18] H. Laaksonen and K. Kauhaniemi, "Voltage and Current THD in Microgrid with Different DG Unit and Load Configurations," in Proc. CIRED 2008 Seminar: SmartGrids for Distribution, 2008. 